"This document is the Accepted Manuscript version of a Published Work that appeared in final form in ACS Catalysis, copyright (C) 2017 American Chemical Society after peer review and technical editing by the publisher. To access the final edited and published work see

http://pubs.acs.org/doi/abs/10.1021/acscatal.7b01860

\title{
Hydrogen Bonding Rescues Overpotential in Seven Coordinated Ru Water Oxidation Catalysts
}

Roc Matheu, ${ }^{\mathrm{a}, \mathrm{b}}$ Mehmed Z. Ertem, ${ }^{\mathrm{c}}$ Carolina Gimbert-Suriñach, ${ }^{\mathrm{a}}$ Jordi Benet-Buchholz, ${ }^{\text {a } X a v i e r}$ Sala*,d and Antoni Llobet ${ }^{* a, d}$

a Institute of Chemical Research of Catalonia (ICIQ), Avinguda Països Catalans 16, 43007 Tarragona, Spain.

${ }^{b}$ Departament de Química Física i Inorgànica, Universitat Rovira i Virgili, Marcel·lí Domingo s/n, 43007 Tarragona, Spain.

${ }^{\mathrm{C}}$ Chemistry Division, Energy \& Photon Sciences Directorate, Brookhaven National Laboratory, Upton, New York, 11973-5000, USA

d Departament de Química, Universitat Autònoma de Barcelona, Cerdanyola del Vallès, 08193 Barcelona, Spain.

Corresponding authors: allobet@iciq.es; xavier.sala@uab.cat 


\section{Abstract}

In this work we describe the synthesis, structural characterization and redox properties of two Ru complexes containing the dianionic potentially pentadentate $\left[2,2^{\prime}: 6^{\prime}, 2^{\prime \prime}\right.$-terpyridine]-6,6"dicarboxylate $\left(\mathrm{tda}^{2-}\right)$ ligand that coordinates $\mathrm{Ru}$ at the equatorial plane and with additional pyridine or dmso acting as monondentate ligand in the axial positions: [Ru"(tda- $\kappa$ $\left.\left.\mathrm{N}^{3} \mathrm{O}\right)(\mathrm{py})(\mathrm{dmso})\right], \mathbf{1}^{\prime \prime}$ and $\left[\mathrm{Ru}^{\prime \prime \prime}\left(\mathrm{tda}-\kappa-\mathrm{N}^{3} \mathrm{O}^{2}\right)(\mathrm{py})\left(\mathrm{H}_{2} \mathrm{O}\right)^{\mathrm{ax}}\right]^{+}, \mathbf{2}^{\prime \prime \prime}\left(\mathrm{H}_{2} \mathrm{O}\right)^{+}$. Complex $\mathbf{1}^{\prime \prime}$ has been characterized by single crystal XRD in the solid state and in solution by NMR spectroscopy. The redox properties of $\mathbf{1}^{\prime \prime}$ and $\mathbf{2}^{\prime \prime \prime}\left(\mathrm{H}_{2} \mathrm{O}\right)^{+}$have been thoroughly investigated by means of cyclic voltammetry (CV) and differential pulse voltammetry (DPV). Complex $\mathbf{2}^{\prime \prime}\left(\mathrm{H}_{2} \mathrm{O}\right)$ displays poor catalytic activity with regard to the oxidation of water to dioxygen and its properties have been analyzed based on foot of the wave analysis (FOWA) and catalytic Tafel plots. The activity of $\mathbf{2}^{\prime \prime}\left(\mathrm{H}_{2} \mathrm{O}\right)$ has been compared with related water oxidation catalysts (WOCs) previously described in the literature. Despite its moderate activity, $\mathbf{2}^{\prime \prime}\left(\mathbf{H}_{2} \mathbf{O}\right)$ constitutes the cornerstone that has triggered the rationalization of the different factors that govern overpotentials as well as efficiencies in molecular water oxidation catalysts (WOCs). The present work uncovers the interplay between different parameters namely, coordination number, number of anionic groups bonded to the first coordination sphere of the metal center, water oxidation catalysis overpotential, $p K_{\mathrm{a}}$ and hydrogen bonding and the performance of a given WOC. It thus establishes the basic principles for the design of efficient WOCs operating at low overpotentials.

\section{Keywords:}

Ru complexes, seven coordination, redox properties, water oxidation catalysis, electrocatalysis, water splitting, hydrogen bonding. 


\section{Introduction}

Water oxidation catalysis is a field that has exhibited significant progress over the last ten years mainly powered by the promise of generation of sustainable carbon neutral fuel, based on water splitting. ${ }^{1,2}$ Particularly impressive has been the development of water oxidation catalysts based on transition metal complexes and the understanding of their mechanisms at a molecular level. For the latter the main contribution has been led by Ru complexes where electrochemical, spectroscopic and reactivity studies together with the characterization of some reaction intermediates has generated a significant amount of knowledge in this topic. ${ }^{3}$

The main challenge today in this field is to design and develop rugged and fast catalysts that can be incorporated into a device for overall water splitting at neutral to acidic pHs. To achieve this goal, it is imperative to further understand the factors that govern the catalyst's performance at a molecular level as well as the deactivation pathways that operate in parallel so that they can be avoided. ${ }^{4}$ Molecular transition metal complexes constitute an excellent platform to examine these factors since significant information based on an arsenal of spectroscopic, electrochemical and analytical techniques can be used together with the valuable complementary information provided by computational studies. $5,6,7,8,9,10,11,12,13,14$

The best water oxidation catalysts reported today are based on seven coordinated Ru complexes containing dianionic ligands such as [2,2'-bipyridine]-6,6'-dicarboxylato (bda $\left.{ }^{2-}\right)^{15,16,17}$ and $\left[2,2^{\prime}: 6^{\prime}, 2^{\prime \prime}\right.$-terpyridine]-6,6"-dicarboxylato ( tda $^{2-}$ ) (see Figure 1 for drawn structures of these ligands). Particularly impressive is the seven coordinate complex $\left[\mathrm{Ru}^{\mathrm{IV}}\left(\mathrm{tda}-\kappa-\mathrm{N}^{3} \mathrm{O}\right)(\mathrm{py})_{2}(\mathrm{O})^{\mathrm{eq}}\right]$, $4^{\mathrm{IV}}(0)$, (the superscript in roman numbers indicates the formal oxidation state of Ru; py is pyridine; the "eq" superscript means equatorial) that is capable of oxidizing water to dioxygen at maximum turnover frequencies ( TOF $_{\text {MAX }}$ ) of $7,700 \mathrm{~s}^{-1}$ and $50,000 \mathrm{~s}^{-1}$ at $\mathrm{pH}=7.0$ and $\mathrm{pH}=10.0$ respectively. ${ }^{18}$ In addition, this catalyst achieves turnover numbers (TONs) above one million when anchored into graphitic solid electrodes. ${ }^{19}$ One of the key features for the unprecedented performance of this catalyst is the presence of a non-coordinated carboxylate that acts as an intramolecular proton acceptor at the $\mathrm{O}-\mathrm{O}$ bond formation step, which decreases the energy requirement for the rate determining step. ${ }^{18}$

In an attempt to shed more light into the different factors that influence WOC performance and to come up with a consistent, integrative and unified model, we have prepared new Ru

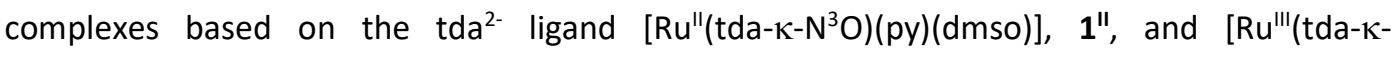
$\left.\left.\mathrm{N}^{3} \mathrm{O}^{2}\right)(\mathrm{py})\left(\mathrm{H}_{2} \mathrm{O}\right)^{\mathrm{ax}}\right]^{+}, \mathbf{2}^{\prime \prime \prime}\left(\mathrm{H}_{2} \mathrm{O}\right)^{+}$. We have thoroughly described their redox properties and compared them with relevant complexes previously described in the literature. We have further performed density functional theory (DFT) calculations to offer a complete view of the catalytic mechanism of this new water oxidation catalyst and to examine the role of coordination number, number of anionic groups bonded to the first coordination sphere of the metal center and $\mathrm{p} K_{\mathrm{a}} \mathrm{s}$ on water oxidation catalysis overpotential of a set of relevant complexes. 


\section{Results}

\subsection{Synthesis and structure}

$\left[\mathrm{Ru}^{\prime \prime} \mathrm{Cl}_{2}(\mathrm{dmso})_{4}\right]$ is used as a starting material to prepare [Ru"(tda- $\left.\left.\kappa-\mathrm{N}^{3} \mathrm{O}\right)(\mathrm{py})(\mathrm{dmso})\right], \mathbf{1}^{\prime \prime}$, that when treated with neat triflic acid and water under an open atmosphere generates [ $\mathrm{Ru}^{\prime \prime \prime}$ (tda- $\mathrm{K}$ $\left.\left.\mathrm{N}^{3} \mathrm{O}^{2}\right)(\mathrm{py})\left(\mathrm{H}_{2} \mathrm{O}\right)^{\mathrm{ax}}\right]^{+}, \mathbf{2}^{\mathrm{II \prime}}\left(\mathrm{H}_{2} \mathrm{O}\right)^{+}$, as indicated in equations 1-2.

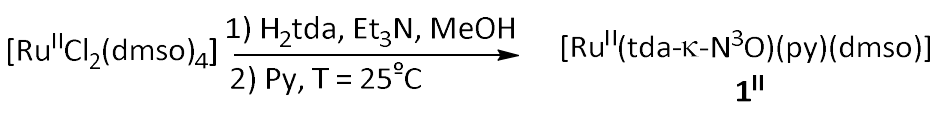

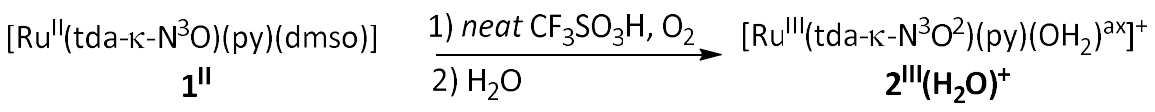

Complex 1" has been structurally characterized in solution by NMR spectroscopy and in the solid state by single crystal X-ray diffraction analysis. An Ortep plot is presented in Figure 1 where the metal center shows a distorted octahedral geometry with the tda ${ }^{2-}$ ligand acting in $\kappa-\mathrm{N}^{3} \mathrm{O}$ fashion in the equatorial zone with one non-coordinated carboxylate group. Finally, a pyridyl and a dmso ligands complete the axial positions. NMR spectroscopy corroborates that the solid state structure is basically maintained in solution. A one electron reduction of $2^{\prime \prime \prime}\left(\mathrm{H}_{2} \mathrm{O}\right)^{+}$generates $\mathbf{2}^{11}\left(\mathrm{H}_{2} \mathrm{O}\right)$ in situ and its ${ }^{1} \mathrm{H}-\mathrm{NMR}$ spectrum shows symmetrical features for the $\mathrm{tda}^{2-}$ resonances indicating the existence of a fast dynamic process where the two carboxylato groups of the tda ${ }^{2-}$ ligand coordinate and decoordinate very fast in a synchronized manner at room temperature (all the NMR spectra are presented in the $\mathrm{SI}$ ). The optimized structures at M06 level of theory ${ }^{20,21}$ indicate that $\mathrm{\kappa}-\mathrm{N}^{3} \mathrm{O}$ binding is favored for $\mathbf{2}^{\prime \prime}\left(\mathrm{H}_{2} \mathrm{O}\right)$ supporting the dynamic nature of coordination of carboxylato groups. On the other hand for $2^{\prime \prime \prime}\left(\mathrm{H}_{2} \mathrm{O}\right)^{+}$a $\kappa-\mathrm{N}^{3} \mathrm{O}^{2}$ mode is favored by DFT with a Ru-N distance of $2.50 \AA$ for the central pyridyl group of the trpy ligand, that suggests an overall "6.5" coordination number as has been previously reported in related complexes ${ }^{18}$ (see Figure $1 C-D)$.

\subsection{Redox Properties and water oxidation catalysis}

The redox properties of the complexes reported here have been investigated based on cyclic voltammetry (CV) and differential pulse voltammetry (DPV) techniques using a three electrode configuration with a glassy carbon disk as a working electrode, a Pt wire as auxiliary electrode and a $\mathrm{Hg} / \mathrm{Hg}_{2} \mathrm{SO}_{4}$ as a reference electrode. All potentials were converted to $\mathrm{NHE}$ by adding 0.65 V.

At $\mathrm{pH}=7.0$ the blank corrected $\mathrm{CV}$ for the Ru-aqua complex $\mathbf{2}^{\prime \prime}\left(\mathrm{H}_{2} \mathrm{O}\right)$ shows two one-electron chemically reversible waves that are associated with the IV/III and III/II redox couples and a small increase on current density in the 1.3-1.5 V zone that is associated with the V/IV couple and water oxidation catalysis as exhibited in Figure $2 \mathrm{~A}$. The small intensity of this wave indicates that 
$\mathbf{2}^{\prime \prime}\left(\mathrm{H}_{2} \mathrm{O}\right)$ is actually a very poor water oxidation catalyst. In addition, the electrochemical response of its homologue, $4^{\mathrm{IV}}(\mathrm{OH})^{+}$that we have reported earlier, is also shown for comparative purposes. Note that $4^{\mathrm{IV}}(\mathrm{OH})^{+}$is generated from $\left[\mathrm{Ru}^{\mathrm{IV}}\left(\mathrm{tda}-\kappa-\mathrm{N}^{3} \mathrm{O}^{2}\right)(\mathrm{py})_{2}\right]^{2+}, 4^{\mathrm{IV}, 2+}$, that has no hydroxido species bonded to $\mathrm{Ru}$, and that both species are present in solution as can be seen in Figure 2A. ${ }^{18} \mathrm{~A}$ complete Pourbaix diagram is offered in Figure $2 \mathrm{~B}$ where the zones of predominant species derived from $\mathbf{2}^{\prime \prime}\left(\mathrm{H}_{2} \mathrm{O}\right)$ with different electron/proton content are shown. An interesting feature of the Pourbaix diagram for $2^{1 \mathrm{~V}}(\mathbf{O H})^{+}$is the $\mathrm{pH} 10-14$ zone, that has been built by extrapolating the values of the $\mathrm{V} / \mathrm{IV}$ couple at this $\mathrm{pH}$ and by assuming that the redox potential for the $\mathrm{Ru}^{\mathrm{V}}=\mathrm{O} / \mathrm{Ru}^{\mathrm{IV}}=\mathrm{O}$ couple for $\left[\mathrm{Ru}^{\mathrm{IV}}(\mathrm{bda})(\mathrm{Me}-\mathrm{py})_{2}(\mathrm{O})^{\mathrm{eq}}\right], \mathbf{3}^{\mathrm{IV}}(\mathrm{O})(1.12 \mathrm{~V}),^{15}$ is the same as for $\mathbf{2}^{\mathrm{iV}}(\mathbf{O})$ (Me-py is 4-methylpyridine). This assumption is based on Lever's approach ${ }^{22,23,24}$ where it is shown that the Ru'I/Rull couple for a set of complexes can be calculated based on additive contribution of their respective ligands bonded to the first coordination sphere. In the present case, complexes $\mathbf{2}^{\mathrm{IV}}(\mathbf{0})$ and $\mathbf{3}^{\mathrm{IV}}(\mathbf{O})$ can be considered as "pseudo isomers" since in both cases the first coordination sphere is occupied by 4 pyridyl groups, two carboxylato and one terminal oxo ligand (see drawn structures Chart 1). Using this value for the V/IV redox potential and assuming a Nernstian behavior we could determine the $p K_{\mathrm{a}}$ for the $\mathrm{Ru}^{\mathrm{IV}}-\mathrm{OH} / \mathrm{Ru}^{\mathrm{IV}}-\mathrm{O}$ couple as 13.5 , at the $E^{\circ}(\mathrm{V} / \mathrm{IV})$ slope change as shown in Figure $2 \mathrm{~B}$. These assumptions are further supported by computed oxidation potentials and $\mathrm{p} K_{\mathrm{a}} \mathrm{S}$ (Table 1 ). Firstly, the computed potentials at $\mathrm{pH} 0$ for $\mathrm{Ru}^{\text {III }-} \mathrm{OH}_{2} / \mathrm{Ru}^{\text {II }}-\mathrm{OH}_{2}(0.43 \mathrm{~V})$ and $\mathrm{Ru}^{\mathrm{IV}}-\mathrm{OH}_{2} / \mathrm{Ru}^{\mathrm{III}}-\mathrm{OH}_{2}(0.79 \mathrm{~V})$ couples for $2^{\prime \prime}\left(\mathrm{H}_{2} \mathrm{O}\right)$ are within $\cong 0.2 \mathrm{~V}$ compared to those reported in experimental Pourbaix diagram in Figure $2 \mathrm{~B}$. The computed potentials for $\mathrm{Ru}^{\mathrm{V}}-\mathrm{O} / \mathrm{Ru}^{\mathrm{IV}}-\mathrm{OH}\left(\right.$ at $\mathrm{pH}=0$ ) and $\mathrm{Ru}^{\mathrm{V}}-\mathrm{O} / \mathrm{Ru}^{\mathrm{IV}}-\mathrm{O}$ are $1.67 \mathrm{~V}$ and $0.97 \mathrm{~V}$ respectively, in line with the predicted potentials with Lever's approach as described above. Finally, the computed $\mathrm{p} K_{\mathrm{a}}$ for $\mathrm{Ru}^{\mathrm{IV}}-\mathrm{OH} / \mathrm{Ru}^{\mathrm{IV}}-\mathrm{O}$ couple is 11.8 , again in good agreement with experimental estimation (Table 1).

A quantitative evaluation of the catalytic properties of $2^{1 \mathrm{~V}}(0)$ was carried out based on the Foot of the Wave Analysis (FOWA). ${ }^{25}$ Using this methodology we obtain a TOF $\max =0.4 \mathrm{~s}^{-1}$ for $\mathbf{2}^{\mathrm{IV}}(\mathbf{0})$ whereas for $\mathbf{4}^{\mathrm{IV}}(\mathbf{0})$ under the same conditions and at nearly the same overpotential we get a $\mathrm{TOF}_{\text {max }}=7,900 \mathrm{~s}^{-1}$, that is more than 4 orders of magnitude higher. A catalytic Tafel plot is also reported in Figure $2 \mathrm{C}$ for $\mathbf{2}^{\mathrm{IV}}(0), \mathbf{3}^{\mathrm{IV}}(0)$ and $\mathbf{4}^{\mathrm{IV}}(0)$ for comparative purposes. A catalytic cycle based on DFT calculations has been carried out for $2^{\mathrm{IV}}(0)$, that agrees with the available experimental data and parallels that of $4^{1 \mathrm{~V}}(0) \cdot{ }^{18}$ DFT calculations were performed at M06 level of theory ${ }^{20}$ with SMD aqueous continuum solvation mode ${ }^{21}$ to account for bulk solvation effects and optimized transition state structures for $\mathrm{O}-\mathrm{O}$ bond formation. The main features of this catalytic cycle are shown in Figure 3, and further details are presented in the supporting information (SI).

The main difference between the catalytic cycle for $4^{1 \mathrm{~V}}(0)$ and $\mathbf{2}^{\mathrm{IV}}(0)$ is the fact that for the latter the $\mathrm{Ru}^{\mathrm{v}}-\mathrm{O}$ active group is situated in the axial position (Chart 1 ) and thus has no access to efficient intramolecular hydrogen bonding at the critical O-O bond formation step as can be seen in optimized TS (Figure 3). The computed free energy of activation $\left(\Delta G^{\ddagger}\right)$ for O-O bond formation step is now $31.0 \mathrm{kcal} / \mathrm{mol}$ for catalyst $\mathbf{2}^{\mathrm{IV}}(0)$, which is $5.2 \mathrm{kcal} / \mathrm{mol}$ higher than for $\mathbf{4}^{\mathrm{IV}}(0)$, in line with their relative rates of water oxidation. Again these results manifest the facilitating role of a pendant base as a proton acceptor in O-O bond formation via water nucleophilic attack (WNA) pathway. 


\section{Discussion}

3.1 The $R u^{v}=O / R u^{i v}=O$ redox couple and the anionic nature of the ligands.

Mononuclear mono-aqua Ru complexes containing polypyridyl type of ligands such as $\mathbf{2}^{\prime \prime}\left(\mathbf{H}_{\mathbf{2}} \mathbf{O}\right)$, can undergo a series of electron transfer and/or PCET processes to reach high oxidation states that are capable of promoting the oxidation of water to dioxygen. In most cases the active species are based on the $\mathrm{Ru}^{\mathrm{V}}=\mathrm{O} / \mathrm{Ru}^{\mathrm{IV}}=\mathrm{O}$ couple or the corresponding $\mathrm{Ru}^{\mathrm{IV}}-\mathrm{OH}$ species depending on the $\mathrm{pH}$. It is thus of fundamental importance to understand how to influence the redox potential of this couple so that efficient catalysts can be designed with overpotentials close to the thermodynamic value of the $4 \mathrm{H}^{+} / 4 \mathrm{e}^{-}$water oxidation pathway. Intuitively, the electronic perturbation of the metal center can be achieved directly with ligands containing anionic groups that occupy the first coordination sphere of the metal center or in a remote manner by adding electron donating or withdrawing groups attached at the pyridyl backbone of the auxiliary ligands. The latter strategy has been developed in a number of occasions, ${ }^{16,26,27}$ but the results obtained in terms of potential change in high oxidation states are very poor as well as on improving TOFs. On the other hand, the first strategy has proven to be very successful especially using additional carboxylato groups attached to the pyridyl backbone that can directly coordinate to the metal center when compared to auxiliary ligands containing pyridyl groups only.

Figure 4A shows the correlation that can be established for 6 coordinated (CN6) octahedral Ru complexes between the $\mathrm{Ru}^{\mathrm{V}} / \mathrm{Ru}^{\mathrm{IV}}$ redox couple and the number of anionic units contained in the auxiliary ligands of the complex, defined as " $n$ ". Indeed the redox potential of this couple

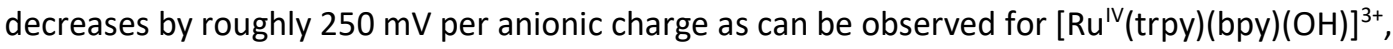
$6^{\text {IV }}(\mathrm{OH})^{3+}$ (zero charges, $\left.n^{-}=0\right),{ }^{27}\left[\mathrm{Ru}^{\mathrm{IV}}(\mathrm{trpy})(\mathrm{ppc})(\mathrm{OH})\right], \mathbf{7}^{\mathrm{IV}}(\mathrm{OH})^{2+}(\mathrm{Hppc}=$ ethyl 3-(pyridin-2-yl)$1 \mathrm{H}$-pyrazole-5-carboxylate, $\left.n^{-}=1\right){ }^{28}\left[\mathrm{Ru}^{\mathrm{IV}}(\mathrm{bca})(\mathrm{py})_{2}(\mathrm{OH})\right]^{2+}, \mathbf{8}^{\mathrm{IV}}(\mathrm{OH})^{2+}\left(\mathrm{Hbca}=2,2^{\prime}\right.$-bipyridne-6carboxylic acid; $\left.n^{-}=1\right)^{29}$ and trans- $\left[\mathrm{Ru}^{\mathrm{IV}}(\mathrm{pdc})(\mathrm{Me}-\mathrm{py})_{2}(\mathrm{OH})\right]^{+}, \mathbf{9}^{\mathrm{IV}}(\mathrm{OH})^{+}\left(\mathrm{H}_{2} \mathrm{pdc}=\right.$ pyridine-2,6dicarboxylic acid; $n^{-}=2$ ). ${ }^{30}$ (see Figure $4 \mathrm{~B}$ for a drawing of these complexes). The computed potentials for $\mathrm{Ru}^{\mathrm{V}}=\mathrm{O} / \mathrm{Ru}^{\mathrm{IV}}=\mathrm{O}$ couples at $\mathrm{MO6}$ level of theory exhibit a similar trend and are shown in parenthesis in Table 1 . The same trend can be observed for seven coordinated (CN7) complexes in the cases of $\left[\mathrm{Ru}(\operatorname{trpc})(\mathrm{Me}-\mathrm{py})_{2}(\mathrm{OH})\right], \mathbf{5}^{\mathrm{IV}}(\mathrm{OH})^{3+}\left(\mathrm{Htrpc}=2,2^{\prime}: 6^{\prime}, 2^{\prime \prime}\right.$-terpyridine-6carboxylate; $\left.n^{-}=1\right),{ }^{31} 4^{\mathrm{IV}}(\mathrm{OH})^{+}\left(n^{-}=1\right), 3^{\mathrm{IV}}(\mathrm{OH})^{+}\left(n^{-}=2\right)$ and $2^{\mathrm{IV}}(\mathrm{OH})^{+}\left(n^{-}=2\right)$, but with a decrease of approx. $200 \mathrm{mV}$ with regard to their corresponding CN6 counterparts due to the addition of one more ligand at the first coordination sphere of $\mathrm{Ru}$. The trend is similar for computed potentials for $\mathrm{CN} 7$ complexes and even the shift from $\mathrm{CN} 6$ counterparts are well reproduced with the exception of $9^{\mathrm{IV}}(\mathrm{OH})^{+}$for which the difference between experiment and theory is the largest, a fact that is not well understood at present (Table 1). In all cases, the complexes used to stablish this correlation remain intact after catalysis ensuring the virtuosity of this correlation. The stability of the catalysts is corroborated by the chemical reversibility of the non catalytic waves after the eletrocatalytic process. Unfortunately this is not the case for the $2,2^{\prime}: 6$ ', $2^{\prime \prime}: 6^{\prime \prime}, 2^{\prime \prime \prime}$-quaterpyridine (qtpy) complex [Ru"(qtpy)(py) 2$]^{2+}$, a potential example of CN7, $n^{-}$ $=0$, where a recent report indicates that it undergoes multiple pyridyl oxidation forming the corresponding $\mathrm{N}$-oxide and thus is not considered in this work. ${ }^{32}$ 


\subsection{The $\mathrm{pH}$ dependency of the $R u^{v}=O / R u^{I V}=O$ redox couple and WOC overpotential.}

The $\mathrm{pH}$-dependency of the $\mathrm{Ru}^{\mathrm{V}} / \mathrm{Ru}^{\mathrm{IV}}$ couple is shown in Figure $4 \mathrm{C}$ for representative water oxidation catalysts $2^{\mathrm{IV}}(\mathrm{OH})^{+}, 3^{\mathrm{IV}}(\mathrm{OH})^{+}, 4^{\mathrm{IV}}(\mathrm{OH})^{+}$and $6^{\mathrm{IV}}(\mathrm{OH})^{+}$. The $\mathrm{Ru}^{\mathrm{V}}-\mathrm{OH}$ species is very acidic for the complexes discussed here and thus their $\mathrm{p} K_{\mathrm{a}}$ is always lower than zero. In sharp contrast, for these complexes in oxidation state IV their $\mathrm{p} K_{\mathrm{a}}$ drastically changes from values lower than zero all the way up to 13.5 as shown in Table 1 and Figure 4C. Thus, the value of the V/IV redox couple over $\mathrm{pH}$ is strongly influenced by the acidity of the $\mathrm{Ru}^{\mathrm{IV}}-\mathrm{OH}$ group that is by its $p K_{a}$. Two extreme cases shown in Figure $4 \mathrm{C}$ illustrate this point. For complex $6^{\mathrm{IV}}(\mathrm{OH})^{+}$the $p K_{a}<0\left(\mathrm{p} K_{\mathrm{a}}^{\text {calc }}=-8.9\right)$ and thus the predominant species over the whole $0-14 \mathrm{pH}$-range is the $\mathrm{Ru}^{\mathrm{IV}}=\mathrm{O}$. Therefore, the couple is $\mathrm{pH}$ independent (see red line in Figure $4 \mathrm{C}$ ) and only an electron transfer process occurs in this case. On the other hand, for complex $2^{\mathrm{IV}}(\mathbf{O H})^{+}$the $\mathrm{p} K_{\mathrm{a}}$ is $13.5\left(p K_{a}^{\text {calc }}=11.8\right)$ and thus for this complex the $\mathrm{Ru}^{\mathrm{IV}}-\mathrm{OH}$ is the predominant species over the $\mathrm{pH}$ range 0-13.5 (black line Figure $4 \mathrm{C})$. As a consequence of this, within this $\mathrm{pH}$ range the electron transfer is accompanied with proton removal in a typical PCET process with $59 \mathrm{mV}$ per $\mathrm{pH}$-unit decrease according to the Nernst equation. This situation produces a radically different scenario with regard to water oxidation overpotential for these couples as a function of $\mathrm{pH}$. For instance, at $\mathrm{pH}=0,6^{\mathrm{IV}}(\mathbf{0})^{2+}$ has an overpotential of $590 \mathrm{mV}$ whereas for $2^{\mathrm{iV}}(\mathbf{O H})^{+}$this increases up to $680 \mathrm{mV}$. On the other hand, shifting the $\mathrm{pH}$ up to 13.5 does not change the overpotential for $2^{\text {IV }}(\mathbf{O H})^{+}$but in sharp contrast that of $6^{\mathrm{IV}}(\mathrm{O})^{2+}$ increases all the way to $1400 \mathrm{mV}$.

Another interesting feature that can be observed in Figure $4 \mathrm{C}$ is the effect of the number of anionic groups coordinated to the metal center in seven coordinated complexes that have the same $\mathrm{p} K_{\mathrm{a}}$, that is comparing complex $3^{\mathrm{iv}}(\mathrm{OH})^{+}$and $4^{\mathrm{IV}}(\mathrm{OH})^{+}$, brown and blue lines in Figure $4 \mathrm{C}$ respectively. In this case the potentials are virtually parallel to one another and thus the overpotential is $300 \mathrm{mV}$ lower for $\mathbf{3}^{\mathrm{IV}}(\mathbf{O H})^{+}$than for $\mathbf{4}^{\mathrm{IV}}(\mathbf{O H})^{+}$over the whole $\mathrm{pH}$ range.

Finally, it is also worth comparing complexes $2^{\mathrm{iV}}(\mathrm{OH})^{+}$and $3^{\mathrm{IV}}(\mathrm{OH})^{+}\left(\mathrm{p} K_{\mathrm{a}}^{\text {calc }}=6.8\right)$ that have the same $\mathrm{Ru}(\mathrm{V} / \mathrm{IV}$ ) potentials at $\mathrm{pH} 13.5$, because they are pseudo-isomers, but that have radically different $p K_{\mathrm{a}}$ values (see black and brown lines respectively in Figure 4C). At pH 13.5 they have identical overpotentials of $720 \mathrm{mV}$ but at $\mathrm{pH} 6,3^{\mathrm{IV}}(\mathrm{OH})^{+}$decreases its overpotential by $390 \mathrm{mV}$ with regard to $2^{\mathrm{iv}}(\mathrm{OH})^{+}$that keeps constant up to the whole $\mathrm{pH}$-range.

\subsection{The $p K_{a}$ of the $R u^{\prime V}-O H / R u^{\prime v}=O$ couple.}

In the previous sections, we have put forward the importance of increasing the coordination number as well as the number of anionic groups contained in the auxiliary ligands in order to reduce the redox potentials of the V/IV couple. However, strongly increasing the electron density at the metal center in this manner not only reduces the redox potential but also drastically decreases the acidity of $\mathrm{Ru}^{\mathrm{IV}}-\mathrm{OH}$ and thus increases its $p K_{\mathrm{a}}$. A paradigmatic example of the interplay between redox potential and $p K_{\mathrm{a}}$ is the comparison of redox potentials discussed above for $6^{\mathrm{IV}}(\mathrm{O})^{2+}$ and $\mathbf{2}^{\mathrm{IV}}(\mathrm{OH})^{+}$. At $\mathrm{pH} 13.5$ for $\mathbf{2}^{\mathrm{IV}}(\mathrm{OH})^{+}$the redox potential is drastically reduced compared to $6^{\mathrm{IV}}(0)^{2+}$, but at $\mathrm{pH}=0$ its redox potential is actually higher than that of $6^{\mathrm{IV}}(0)^{2+}$. 
Thus, a key question that arises here is which are the factors that influence the $p K_{\mathrm{a}}$ of this couple and how can they be manipulated given its key role on the overpotential in WOCs. In other words, how can we strongly decrease redox potentials but without increasing the $p K_{\mathrm{a}}$ ? The answer to this apparently contradictory question is the key to access efficient WOCs with low overpotentials at low $\mathrm{pH}$.

In Table 1 are gathered the experimental and computed $p K_{\mathrm{a}}$ values for the $\mathrm{Ru}{ }^{\mathrm{IV}}-\mathrm{OH}$ species for the complexes studied here and for some other related complexes relevant for the presented discussion. A few conclusions can be extracted from this table,

- For six coordinated complexes $6^{1 \mathrm{~V}}(0)^{2+}$ and $\mathbf{7}^{1 \mathrm{~V}}(0)^{2+}$ with zero and one anionic charge respectively, their $\mathrm{Ru}^{\mathrm{IV}}-\mathrm{OH}$ species are highly acidic with $\mathrm{p} K_{\mathrm{a}}{ }^{\prime} \mathrm{s}<0$ and thus their $\mathrm{V} / \mathrm{IV}$ couple is $\mathrm{pH}$ independent over the whole $\mathrm{pH}$ range. Theory also predicts $\mathrm{p} K_{\mathrm{a}}$ 's $<0$ for complexes with zero and one anionic charges $6^{1 \mathrm{~V}}(\mathrm{OH})^{3+}, 7^{1 \mathrm{~V}}(\mathrm{OH})^{2+}$ and $\mathbf{8}^{\mathrm{IV}}(\mathrm{OH})^{2+}$, whereas the six coordinated complex with a dianionic ligand, $9^{\mathrm{IV}}(\mathrm{OH})^{+}$, is predicted to be less acidic with a $p K_{\mathrm{a}}^{\text {calc }}=2.9$.

- The six coordinated complex, $6^{1 \mathrm{~V}}(\mathrm{OH})^{3+}$, with zero charge on the ligand is predicted to be very acidic with a $p K_{\mathrm{a}}^{\text {calc }}=-8.9$, but for $2^{\mathrm{iV}}(\mathrm{OH})^{+}$, that contains two anionic charges with an aqua ligand positioned axially, the $p K_{\mathrm{a}}$ spectacularly increases up to $13.5\left(p K_{\mathrm{a}}^{\text {calc }}=11.8\right)$.

- For $3^{1 \mathrm{i}}(\mathrm{OH})^{+}$with two anionic charges and CN7 but with significant intramolecular $\mathrm{H}-$ bonding at the equatorial zone between the $\mathrm{Ru}-\mathrm{OH}$ group and the neighboring Ru-carboxylato group ( $\mathrm{d}_{\mathrm{O}-\mathrm{H}-- \text {-Ocarboxylato }}=2.174 \AA \AA^{\wedge}{ }^{\wedge}$ HO-Ru-Ocarboxylato $\left.=73.8^{\circ}\right),{ }^{33}$ displays a $p K_{a}=6.0\left(p K_{\mathrm{a}}^{\text {calc }}=6.8\right)$. This is in sharp contrast with its pseudo isomer $2^{1 \mathrm{~V}}(\mathbf{O H})^{+}$, that has the same number of anionic charges but no intramolecular $\mathrm{H}$-bonding with a has a $p K_{\mathrm{a}}=13.5\left(p K_{\mathrm{a}}^{\text {calc }}=11.8\right)$. Thus the hydrogen bonding here is responsible for increasing the acidity by more than 7 orders of magnitude. This $p K_{\mathrm{a}}$ shift is then responsible for the stabilization of the $\mathrm{V} / \mathrm{IV}$ redox potential at low $\mathrm{pH}$ which is important since there are very few WOCs operative at low overpotentials in such acidic conditions.

- Finally, for the seven coordinated complex $4^{\mathrm{IV}}(\mathrm{OH})^{+}$with one anionic donor group but with intramolecular hydrogen bonding has a $\mathrm{p} K_{\mathrm{a}}$ of $5.7\left(p K_{\mathrm{a}}^{\mathrm{calc}}=5.4\right)$. similar to $3^{\mathrm{IV}}(\mathrm{OH})^{+}$.

\subsection{Catalysis}

In the previous section, we have uncovered the role of hydrogen bonding in increasing the $\mathrm{p} K_{\mathrm{a}}$ of the $\mathrm{Ru}(\mathrm{IV})-\mathrm{OH}$ species, a thermodynamic effect. Further, it is interesting to see here that for $2^{\mathrm{IV}}(\mathrm{OH})^{+}$at $\mathrm{pH}=7$, the overpotential is about $100 \mathrm{mV}$ higher than for $4^{\mathrm{IV}}(\mathrm{OH})^{+}$, yet the latter oxidizes water to dioxygen 3 orders of magnitude faster than the former, as can be graphically observed in the Tafel plot in Figure $2 \mathrm{C}$. This has been associated with the role of the dangling carboxylate that acts as intramolecular base accepting a proton from the incoming water molecule at the $\mathrm{O}-\mathrm{O}$ bond formation step and thus reducing the energy of activation, a kinetic effect (Figure 4). Thus the dangling carboxylate in complex $4^{\mathrm{IV}}(\mathbf{O H})^{+}$has a dual role of favoring both thermodynamics and kinetics. In the same line, it is also interesting to realize that $\mathbf{6}^{\mathrm{IV}}(\mathbf{0})^{3+}$ at $\mathrm{pH}=7$ has an overpotential of $650 \mathrm{mV}$ and a TOF of $0.05 \mathrm{~s}^{-1}$ (measured at $\mathrm{pH}=1.0$ ). ${ }^{27}$ This is in sharp contrast to $4^{\mathrm{IV}}(\mathrm{OH})^{+}$that even with a lower $\eta$ of $450 \mathrm{mV}$ has a TOF $\max$ of $7,900 \mathrm{~s}^{-1}$, that 
is more than 5 orders of magnitude faster than that of $6^{1 \mathrm{~V}}(0)^{2+}$, again a consequence of the absence of intramolecular hydrogen bonding and a pendant base in the latter.

Finally, at $\mathrm{pH} 7,3^{\mathrm{IV}}(\mathbf{O H})^{+}$has an overpotential of $300 \mathrm{mV}$ that is the lowest of all complexes discussed here. Under these conditions, $\mathbf{3}^{\mathbf{I V}}(\mathbf{O H})^{+}$reaches a TOF $F_{\max }$ of $25 \mathrm{~s}^{-1}$ as shown in the Tafel plot in Figure 2. For this complex, however it is not possible to establish a direct comparison since it follows an $12 \mathrm{M}$ mechanism whereas the rest of the complexes generate the $\mathrm{O}-\mathrm{O}$ bond formation via a water nucleophilic attack (WNA) mechanism.

\section{Conclusions}

Complex $\left[\mathrm{Ru}^{\mathrm{IV}}(\mathrm{tda})(\mathrm{py})\left(\mathrm{OH}^{\mathrm{ax}}\right)\right]^{+}, \mathbf{2}^{\mathrm{IV}}(\mathrm{OH})^{+}$, with one pyridyl and one hydroxido ligand at the axial positions displays a poor activity with regard to its capacity to oxidize water to dioxygen catalytically. However, it is important because it has fostered the rationalization of the different factors involved in both six and seven coordination Ru WOCs with polypyridyl and related ligands described in the literature. From a thermodynamic perspective these factors include the influence of six and seven coordination on the $\mathrm{Ru}^{\mathrm{V}} / \mathrm{Ru}^{\mathrm{IV}}$ redox couple and the $p K_{a}$ of the $\mathrm{Ru}^{\mathrm{IV}}$ $\mathrm{OH} / \mathrm{Ru}^{\mathrm{IV}}-\mathrm{O}$ species. The latter is strongly influenced by their access to intramolecular hydrogen bonding that is in turn controlled by the relative position of the hydroxido ligand with regard to the auxiliary tda ${ }^{2-}$ ligand. In complex $2^{1 \mathrm{~V}}(\mathrm{OH})^{+}$, the axial position of the hydroxido ligand precludes the presence of intramolecular hydrogen bonding and thus allows quantifying the combined effect of anionic ligands and coordination number when compared to related complexes described in the literature. From a kinetic perspective it is impressive to see the contrast in TOF $=0.4 \mathrm{~s}^{-1}$ for $2^{\mathrm{iV}}(\mathrm{OH})^{+}$with no $\mathrm{H}$-bonding and TOF $=7,900 \mathrm{~s}^{-1}$ for $4^{\mathrm{IV}}(\mathrm{OH})^{+}$, at $\mathrm{pH}=$ 7. For the latter complex the hydroxido ligand is situated in the equatorial plane and is responsible for the $\mathrm{O}-\mathrm{O}$ bond formation with an incoming solvent water molecule that can transfer a proton to the dangling carboxylate in an intramolecular manner.

It is worth mentioning here that for molecular Ru water oxidation catalysts there is in general a very good degree of electrochemical information in the reported papers. This has allowed choosing the correct candidates to establish the present correlation. Unfortunately for other transition metal complexes, the description of their redox properties is not as nice and complete as with Ru complexes, and thus at present this type of analysis is precluded. Nevertheless, if the correct information were available the rationalization established here can certainly be extrapolated to other transition metal water oxidation catalysts.

As a summary, the present work shows how the different factors involved in Ru-WOC can be controlled by the auxiliary ligands and thus pave the way for the design of efficient transition metal based catalysts at low $\mathrm{pH}$ and low overpotentials.

\section{Associated Content}


Supporting Information. Experimental details as well as additional, electrochemical, crystallographic and computational results. This material is available free of charge via the Internet at http://pubs.acs.org.

\section{Acknowledgments}

R.M. thanks "La Caixa" foundation for a PhD grant. A.L. thanks MINECO and FEDER (CTQ-201680058-R, SEV-2013-0319; CTQ-2014-52974-REDC) and "La Caixa" foundation for financial support. The work carried out at Brookhaven National Laboratory (M.Z.E.) was supported by the U.S. Department of Energy, Office of Science, Division of Chemical Sciences, Geosciences, \& Biosciences, Office of Basic Energy Sciences under contract DE-SC00112704. X.S. thanks MINECO and FEDER (CTQ-2015-64261-R) for financial support. 


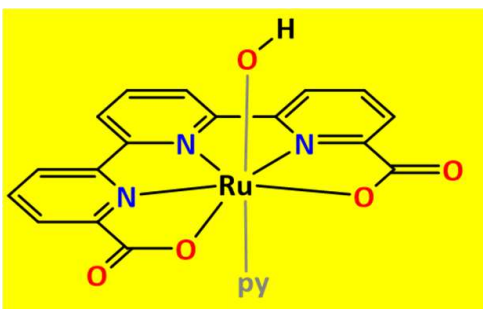

$2^{\text {IV }}(\mathrm{OH})^{+}$

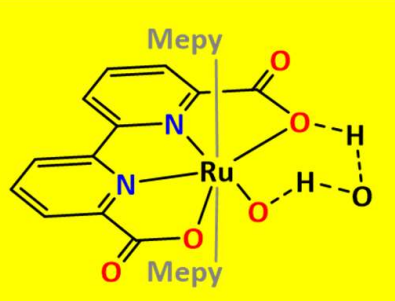

$3^{\mathrm{IV}}(\mathrm{OH})^{+}$

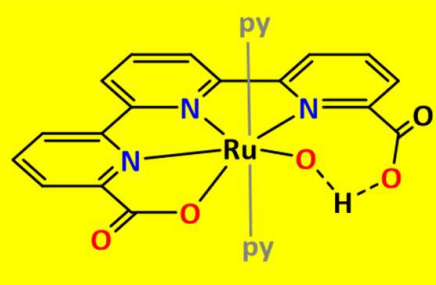

$4^{\text {IV }}(\mathrm{OH})^{+}$

Chart 1: Structure of complexes $2^{1 \mathrm{~V}}(\mathrm{OH})^{+}, 3^{\mathrm{IV}}(\mathrm{OH})^{+}$and $4^{\mathrm{IV}}(\mathrm{OH})^{+}$ 

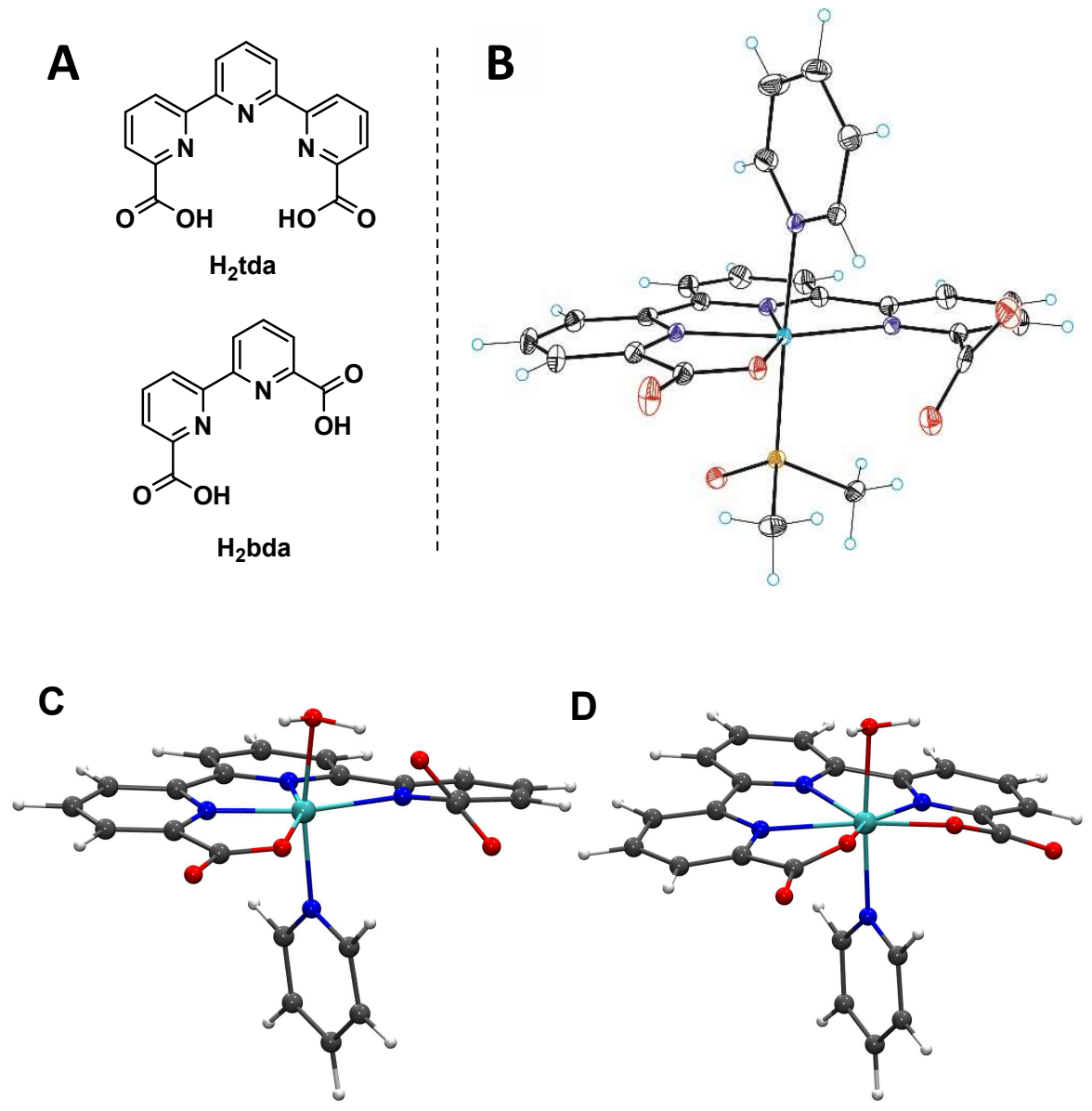

Figure 1: A, Drawing of protonated $\mathrm{bda}^{2-}$ and $\mathrm{tda}^{2-}$ ligands. B, ORTEP plot for complex $1^{11}$ with ellipsoids at $50 \%$ probability. Color code: Ru, cyan; N, purple; O, red; C, black; $\mathrm{S}$, orange; and $\mathrm{H}$, colorless. $\mathrm{C}$, Optimized structures at $\mathrm{M06}$ level of theory for $\left[R u^{\prime \prime}\left(\right.\right.$ tda- $\left.\left.\kappa-N^{3} \mathrm{O}\right)(\mathrm{py})\left(\mathrm{H}_{2} \mathrm{O}\right)^{\mathrm{ax}}\right]$ and $\mathbf{D}$, for $\left[\mathrm{Ru}^{\prime \prime \prime}\left(\mathrm{tda}-\kappa-\mathrm{N}^{3} \mathrm{O}^{2}\right)(\mathrm{py})\left(\mathrm{H}_{2} \mathrm{O}\right)^{\mathrm{ax}}\right]^{+}$. Color code: $\mathrm{Ru}$, cyan; $\mathrm{N}$, blue; $\mathrm{O}$, red; $\mathrm{C}$, gray; and $\mathrm{H}$, white. 

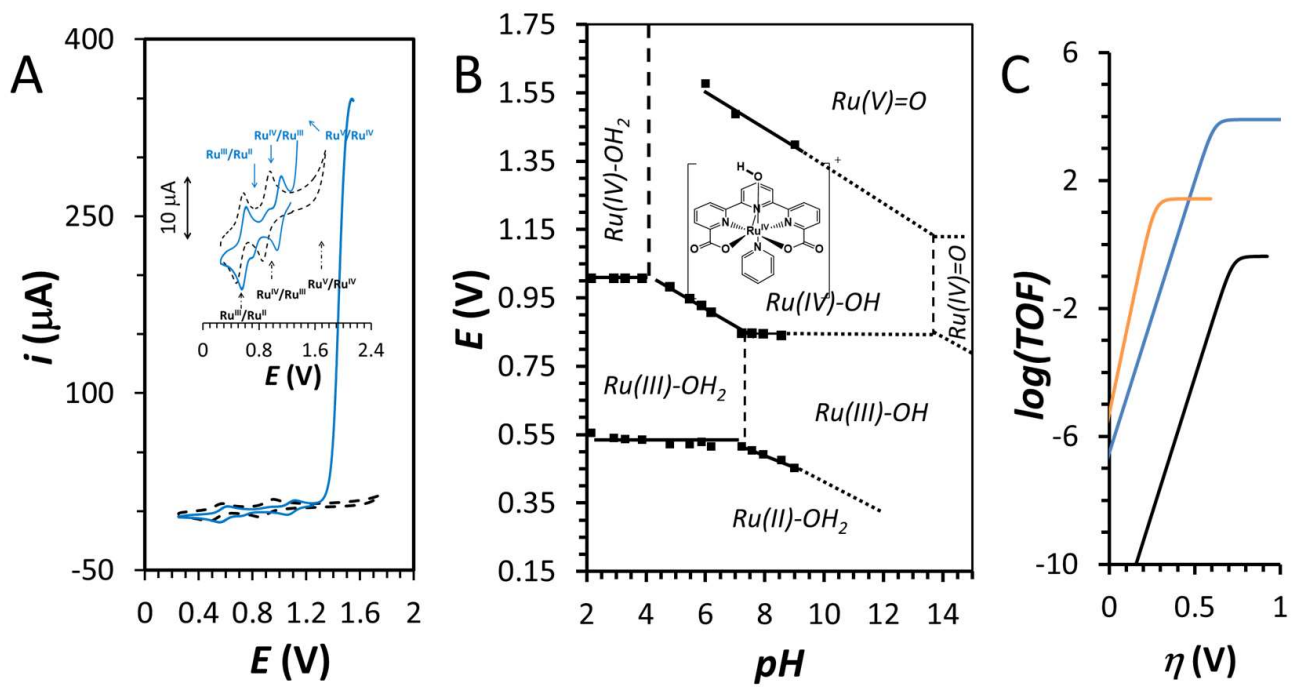

Figure 2: A, blank corrected Cyclic Voltammetry (CV) at $\mathrm{pH}=7.0$ for $\mathbf{2}^{\mathrm{IV}}(\mathbf{0})$ (black dashed line) and $4^{\mathrm{IV}, 2+} / \mathbf{4}^{\mathrm{IV}}(\mathbf{0}) 0.75 \mathrm{mM} / 0.37 \mathrm{mM}$ (blue solid line) at $\mathrm{pH}=7.0$. Inset: enlargement of the $\mathrm{y}$ axis and assignment of redox couples. B, Pourbaix diagram of $2^{11 \prime}\left(\mathbf{H}_{2} \mathbf{O}\right)^{+}$indicating the predominant species in the different $E$-pH zones. Auxiliary ligand tda ${ }^{2-}$ and py are not shown for simplicity. Vertical lines indicate $p K_{a}$ s. Dotted lines indicate redox potentials extrapolated using the Nernst equation. C, catalytic Tafel plot for complexes $\mathbf{2}^{\text {IV }}(\mathbf{0})$ (black line), $\mathbf{3}^{\text {IV }}(\mathbf{0})(0.5$ $\mathrm{mM}$, orange line) and $\mathbf{4}^{\mathrm{IV}}(\mathrm{O})$ (blue line) at $\mathrm{pH}=7.0$. 


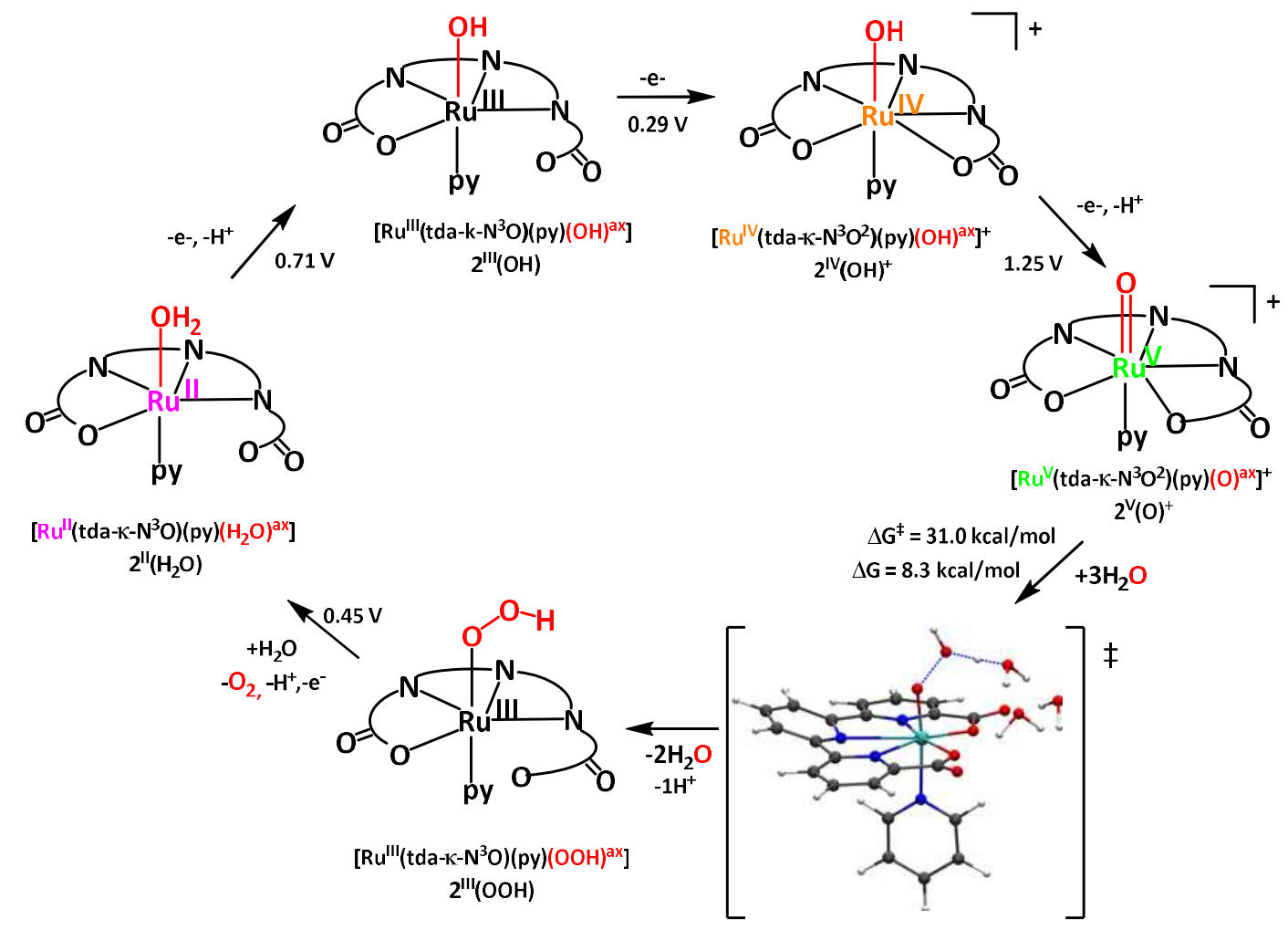

Figure 3. Catalytic water oxidation cycle based on DFT calculations for $2^{\prime \prime \prime}(\mathrm{OH})^{+}$at $\mathrm{pH}=7.0$. The arcs connecting $\mathrm{N}$ and $\mathrm{O}$ atoms represent the $\mathrm{tda}^{2-}$ ligand. Color code for the transition state: $\mathrm{Ru}$, cyan; $\mathrm{N}$, blue; $\mathrm{O}$, red; $\mathrm{C}$, gray; and $\mathrm{H}$, white. 


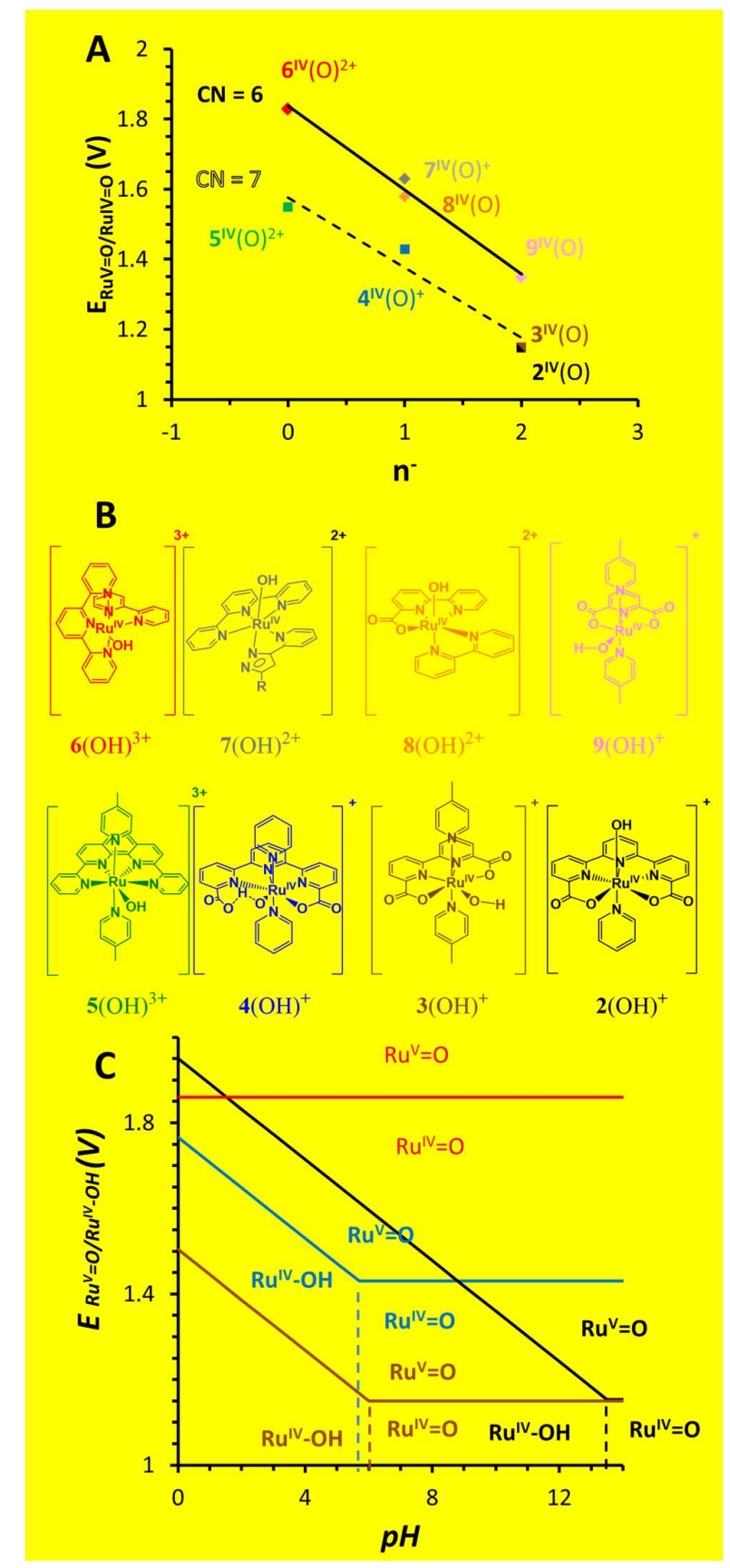

Figure 4. A, Correlation between $\mathrm{Ru}(\mathrm{V})=\mathrm{O} / \mathrm{Ru}(\mathrm{IV})=\mathrm{O}$ redox potential and the number of anionic charges, $\boldsymbol{n}$, contained in the auxiliary ligands bonded to metal center, both for 6 (solid black line) and 7 coordinated catalysts (dashed black line). B, drawn structures for complex $2^{\mathrm{iv}}(\mathbf{O H})^{+}$, $3^{\mathrm{IV}}(\mathrm{OH})^{+}, 4^{\mathrm{IV}}(\mathrm{OH})^{+}, 5^{\mathrm{IV}}(\mathrm{OH})^{3+}, 6^{\mathrm{IV}}(\mathrm{OH})^{3+}, 7^{\mathrm{IV}}(\mathrm{OH})^{2+}, 8^{\mathrm{IV}}(\mathrm{OH})^{2+}$, and $9^{\mathrm{IV}}(\mathrm{OH})^{+}$. C, Overlaid Pourbaix diagrams for the V/IV redox couple for complexes $2^{\text {IV }}(\mathrm{OH})^{+}$(black), $3^{\text {IV }}(\mathrm{OH})^{+}($brown $), 4^{\text {IV }}(\mathrm{OH})^{+}$ (blue) and $6^{\mathrm{IV}}(\mathbf{0})^{+}$(red). 
Table 1: Selected Redox Potentials and $p K_{a}$ values for Complex $2^{\mathrm{iv}}(\mathbf{O H})^{+}$and Related Complexes

\begin{tabular}{|c|c|c|c|c|c|c|c|c|}
\hline Complex & $2^{\mathrm{IV}}(\mathrm{OH})^{+}$ & $3^{\mathrm{IV}}(\mathrm{OH})^{+}$ & $4^{\mathrm{IV}}(\mathrm{OH})^{+}$ & $5^{\text {IV }}(0)^{2+}$ & $6^{\operatorname{lv}}(0)^{2+}$ & $7^{\operatorname{lv}}(0)^{+}$ & $8^{1 \mathrm{~V}}(\mathrm{O})^{+}$ & $9^{I V}(O)$ \\
\hline $\begin{array}{l}\mathrm{Ru}^{\mathrm{IV}}-\mathrm{OH} \text { Coord. } \\
\text { Environment }\end{array}$ & $\begin{array}{c}4 p y, \\
2 \mathrm{COO}^{-}\end{array}$ & $\begin{array}{c}4 \mathrm{py}, \\
2 \mathrm{COO}\end{array}$ & $\begin{array}{c}5 p y, \\
1 \mathrm{COO}\end{array}$ & $\begin{array}{c}5 p y, \\
1000\end{array}$ & $5 p y$ & $\begin{array}{l}4 p y, \\
1 p y r\end{array}$ & $\begin{array}{c}4 p y, \\
1 \mathrm{COO}\end{array}$ & $\begin{array}{c}3 p y, \\
2 \mathrm{COO}\end{array}$ \\
\hline Coord. Number & 7 & 7 & 7 & 7 & 6 & 6 & 6 & 6 \\
\hline $\begin{array}{c}\mathrm{p} K_{a ;} \quad R u^{\prime V}-\mathrm{OH} / R^{\prime \prime}-\mathrm{O} \\
(\text { Calc. })^{b}\end{array}$ & $\begin{array}{l}13.5^{c} \\
(11.8)\end{array}$ & $\begin{array}{c}6.0 \\
(6.8)\end{array}$ & $\begin{array}{l}5.7 \\
(5.4)\end{array}$ & $n a^{d}$ & $\begin{array}{l}<1.0 \\
(-8.9)\end{array}$ & $\begin{array}{l}<1.0 \\
(-7.7)\end{array}$ & $\begin{array}{l}<1.0 \\
(-2.6)\end{array}$ & $\begin{array}{l}\mathrm{na}^{\mathrm{d}} \\
(2.9)\end{array}$ \\
\hline $\begin{array}{c}E^{O} R u^{v}=O / R u^{\prime v}=O(V) \\
(\text { Calc. })^{b}\end{array}$ & $\begin{array}{l}1.12^{\mathrm{c}} \\
(0.97)\end{array}$ & $\begin{array}{l}1.12 \\
(1.04)\end{array}$ & $\begin{array}{l}1.43 \\
(1.26)\end{array}$ & $1.40^{\mathrm{e}}$ & $\begin{array}{c}1.86 \\
(1.76)\end{array}$ & $\begin{array}{c}1.59 \\
(1.60)\end{array}$ & $\begin{array}{c}1.59 \\
(1.33)\end{array}$ & $\begin{array}{l}1.35^{f} \\
(0.95)^{d}\end{array}$ \\
\hline Reference & $t w^{d}$ & 15 & 18 & 31 & 27 & 28 & 29 & 30 \\
\hline
\end{tabular}

a. In this row, py represents the monodentate pyridyl ligand or a pyridyl group of an auxiliary ligand while COOrepresents the carboxylato group of the corresponding ligand. The abbreviation pyr- is for the pyrazolato group.

b. Calculated based on DFT.

c. The $E^{\circ}$ of the $\mathrm{Ru}^{\mathrm{V}}=\mathrm{O} / \mathrm{Ru}^{\mathrm{IV}}=\mathrm{O}$ redox couples of complexes $2^{\mathrm{IV}}(\mathrm{OH})^{+}$and $\mathbf{3}^{\mathrm{IV}}(\mathrm{OH})^{+}$are assumed to be identical and the $p K_{\mathrm{a}}$ was extrapolated from the Pourbaix diagram. See Figure 2B.

d. tw, means this work; na, means not available.

e. Data estimated from the foot of the catalytic wave in Figure 10 in reference 31.

f. Data estimated from the catalytic wave in Figure 1 in reference 30. 


\section{References}

${ }^{1}$ Lewis, N. S. Science 2016, 351, 19201-19209.

2 Llobet, A.; Meyer, F. Angew. Chem. Int. Ed., 2011, 50, 30-33.

${ }^{3}$ (a) X. Sala, S. Maji, R. Bofill, J. Garcia-Anton, L. Escriche and A. Llobet, Acc. Chem. Res., 2014, 47, $504-$ 516. (b) Keidel, A.; López, I.; Staffa, J.; Kuhlmann, U.; Bozoglian, F.; Gimbert-Suriñach, C.; BenetBuchholz, J.; Hildebrandt, P.; Llobet, A. ChemSusChem, 2017, 10, 551-561.

${ }^{4}$ Molecular Water Oxidation Catalysis: A Key Topic for New Sustainable Energy Conversion Schemes. Llobet, A., Ed; John Wiley and Sons Ltd. 2014.

${ }^{5}$ Barnett, S. M.; Goldberg, K. I.; Mayer, J. M. Nat. Chem. 2012, 4, 498-502.

${ }^{6}$ Okamura, M.; Kondo, M.; Kuga, R.; Kurashige, Y.; Yanai, T.; Hayami, S.; Praneeth, V. K. K.; Yoshida, M.; Yoneda, K.; Kawata, S.; Masaoka, S. Nature 2016, 530, 465-468.

7 Sens, C.; Romero, I.; Rodriguez, M.; Llobet, A.; Parella, T.; Benet-Buchholz, J. J. Am. Chem. Soc. 2004, 126, 7798-7799.

${ }^{8}$ Concepcion, J. J.; Tsai, M. K.; Muckerman, J. T.; Meyer, T. J. J. Am. Chem. Soc. 2010, 132, 1545-1557.

${ }^{9}$ Neudeck, S.; Maji, S.; Lopez, I.; Meyer, S.; Meyer, F.; Llobet, A. J. Am. Chem. Soc. 2014, 136, 24-27.

${ }^{10}$ Wasylenko, D. W.; Ganesamoorthy, C.; Henderson, M.; Koivisto, B. D.; Osthoff, H.; Berlinguette, C. P. J. Am. Chem. Soc. 2010, 132, 16094-16106.

${ }^{11}$ D. E. Polyansky, J. T. Muckerman, J. Rochford, R. Zong, R. P. Thummel and E. Fujita, J. Am. Chem. Soc. 2011, 133, 14649-14665.

${ }^{12}$ Shaffer, D. W.; Xie, Y.; Szalda, D. J.; Concepcion, J. J. Inorg. Chem. 2016, 55, 12024-12035.

${ }^{13}$ Schulze, M.; Kunz, V.; Frischmann, P. D.; Würthner, F. Nat. Chem. 2016, 8, 576-583.

${ }^{14}$ Gimbert-Suriñach, C.; Moonshiram, D.; Francas, L.; Planas, N.; Bernales, V.; Bozoglian, F.; Guda, A.; Mognon, L.; López, I.; Hoque, Md A.; Gagliardi, L.; Cramer, C. J.; Llobet, A. J. Am. Chem. Soc. 2016, 138, 15291-15294.

15 Duan, L.; Bozoglian, F.; Mandal, S.; Stewart, B.; Privalov, T.; Llobet, A.; Sun, L. Nat. Chem. 2012, 4, 418423.

${ }^{16}$ Richmond, C. J.; Matheu, R.; Poater, A.; Falivene, L.; Benet-Buchholz, J.; Sala, X.; Cavallo, L.; Llobet, A. Chem. Eur. J. 2014, 20, 17282-17286.

17 Wang, L.; Duan, L.; Wang, Y.; Ahlquist, M. S. G.; Sun, L. Chem. Commun. 2014, 50, 12947-12950.

${ }^{18}$ Matheu, R.; Ertem, M. Z.; Benet-Buchholz, J.; Coronado, E.; Batista, V. S.; Sala, X.; Llobet, A. J. Am. Chem. Soc. 2015, 137, 10786-10795.

${ }^{19}$ Creus, J.; Matheu, R.; Peñafiel, I.; Moonshiram, D.; Blondeau, P.; Benet-Buchholz, J.; García-Antón, J.; Sala, X.; Godard, C.; Llobet, A. Angew. Chem. Int. Ed. 2016, 55, 15382-15386.

${ }^{20}$ (a) Zhao, Y.; Truhlar, D. G. Theor. Chem. Acc. 2008, 120, 215-241. (b) Zhao, Y.; Truhlar, D. G. Acc. Chem. Res. 2008, 41, 157-167.

${ }^{21}$ Marenich, A. V.; Cramer, C. J.; Truhlar, D. G. J. Phys. Chem. B 2009, 113, 6378-6396.

22 Lever, A.B.P. Inorg. Chem., 1990, 29, 1271-1285.

${ }^{23}$ Lever, A. B. P.; Dodsworth, E. S. In Comprehensive Coordination Chemistry, II, Lever, A. B. P., Ed; Elsevier Publishers, 2004. Vol. 2

${ }^{24}$ Masllorens, E.; Rodriguez, M.; Romero, I.; Roglans, A.; Parella, T.; Benet-Buchholz, J.; Poyatos, M.; Llobet, A. J. Am. Chem. Soc 2006, 128, 5306-5307.

${ }^{25}$ Matheu, R.; Neudeck, S.; Meyer, F.; Sala, X.; Llobet, A. ChemSusChem 2016, 9, 3361-3369.

${ }^{26}$ Roeser, S.; Bozoglian, F.; Richmond, C. J.; League, A. B.; Ertem, M. Z.; Francas, L.; Miro, P.; BenetBuchholz, J.; Cramer, C. J.; Llobet, A Cat. Sci. Technol., 2016, 6, 5088-5101.

${ }^{27}$ Wasylenko, D. J.; Ganesamoorthy, C.; Henderson, M. A.; Berlinguette, C. P. Inorg. Chem. 2011, 50, 3662-3672.

${ }^{28}$ Mognon, L.; Benet-Buchholz, J.; Llobet, A. Inorg. Chem. 2015, 54, 11948-11957.

${ }^{29}$ Tong, L.; Inge, A. K.; Duan, L.; Wang, L.; Zou, X.; Sun, L. Inorg. Chem .2013, 52, 2505-2518.

${ }^{30}$ Li, F.; Li, L.; Tong, L.; Daniel, Q.; Gothelid, M.; Sun, L. Chem. Commun. 2014, 50, 13948-13951.

${ }^{31}$ Fan, T.; Duan, L.; Huang, P.; Chen, H.; Daniel, Q.; Ahlquist, M. S. G.; Sun, L. ACS Catal. 2017, 7, 2956-2966. 
${ }^{32}$ Liu, Y.; Ng, S.-M.; Yiu, S.-M.; Lam, W. W. Y.; Wei, X.-G.; Lau, K.-C.; Lau, T.-C. Angew. Chem. Int. Ed. 2014, 53, 14468-14471.

${ }^{33}$ Duan, L.; Fischer, A.; Xu, Y.; Sun, L. J. Am. Chem. Soc. 2009, 131, 10397-10399. 
TOC

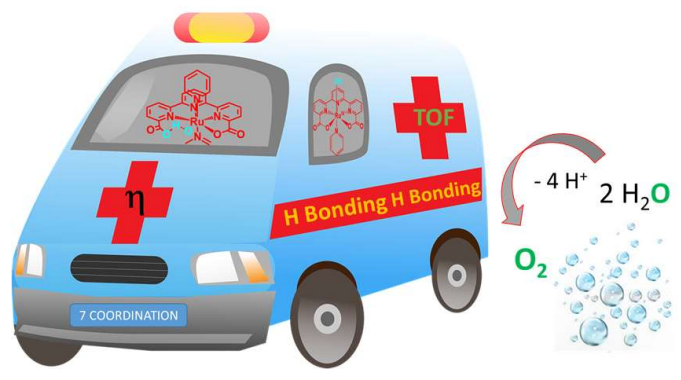

